\title{
Synthesis and biological activity of a number of salicylic acid esters
}

\author{
(C) Natalia A. Bondareva, ${ }^{+}$Peotr P. Purygin, ${ }^{*}$ and Olga O. Isaeva \\ Department of Inorganic Chemistry. Samara University. Moskovskoye shosse, 34. Samara, 443086. \\ Volga Federal District. Samara Region.Russia.Phone: +7 (846) 334-54-59. E-mail: nnkk86@mail.ru
}

*Supervising author; ${ }^{+}$Corresponding author

Keywords: salicylic acid, esters, synthesis of derivatives of salicylic acid.

\begin{abstract}
Salicylic acid is currently of little use, but its derivatives are one of the most large-tonnage drugs in the world. However, the natural sources of salicylic acid cannot satisfy the needs for its preparations and therefore the acid and its derivatives are obtained exclusively by synthetic means. Derivatives of salicylic acid are of great interest, due to their high reactivity and widespread use in medical practice as anti-inflammatory, antipyretic, analgesic, antimicrobial, antiseptic and anti-tuberculosis drugs. Currently, there is a fairly large body of data on the synthesis, structure, and biological properties of various derivatives of salicylic acid, however, it should be noted that derivatives of salicylic acid and various derivatives of amino acids and salicylic acid are poorly studied. The relevance of studying the properties of new transformed derivatives of salicylic acid is due to broad prospects that open the borders for realizing the potential for further chemical modification inherent in the structure of these new substances with a combination of several active groups: carbonyl and hydroxyl. Such a combination in a molecule of derivatives based on salicylic acid, containing known pharmacological groups in its structure, often leads to the appearance of a new high hemostatic activity. In the course of our work, we synthesized some esters based on salicylic acid, and also determined the antiplatelet and anticoagulant activity of the first synthesized substances. The study was conducted on the indicators of coagulogram in vitro on human donated blood. It was found that all provided compounds exhibit anti-aggregation activity, some of the compounds obtained by us exhibit anti-aggregation activity of more than $10 \%$. All the experimental work was performed by us at the Department of Anesthesiology and Intensive Care with the course of the Institute of Continuing and Professional Education of the Bashkir State Medical University of the Ministry of Health of Russia on the basis of the Central Research Laboratory of the Bashkir State Medical University of the Ministry of Health of Russia and GBUZ RKB named after G.G. Kuvatova in accordance with the recommendations of the "Guidelines for the preclinical study of new pharmacological substances."
\end{abstract}

\section{References}

[1] A.K. Brel, S.V. Lisina, Y.N. Budaeva, N.V. Rodina. Synthesis and psychotropic activity of salts of N-(4hydroxybenzoyl) glycine and N-(4-acetoxybenzoyl) glycine. Basic research. 2013. No.10. P.1963-1968. (russian)

[2] A.K. Brel, S.V. Lisina, and Ju.N. Salomatina Salicylamides and their salts as potential psychotropic agents. Butlerov Communications. 2012. Vol.30. No.5. P.55-59. ROI: jbc-02/12-30-5-55

[3] A.K. Brel, S.V. Lisina, and Yu.N. Salomatina. Nitrogen-containing derivatives of oxybenzoic acids. Butlerov Communications. 2012. Vol.32. No.10. P.81-86. ROI: jbc-02/12-32-10-81

[4] A.K. Brel, S.V. Lisina, Yu.N. Salomatina. Synthesis and properties of derivatives of hydroxybenzoic acids. Materials of the annual conference "Pharmacy and public health". Digest of articles. UGMA, Yekaterinburg. 2010. P.143-145. (russian)

[5] Guidelines for preclinical studies of drugs. Part one. Moscow: Grif and K. 2012. 944p. (russian)

[6] V.F. Traven. Organic chemistry study guide for universities. 2013. Vol.1. P.312-313. (russian)

[7] Methods for the production of chemicals and drugs. Chemistry. 1969. Iss.18. P.236-237. (russian) 